\section{IQ data controversy}

\section{London}

THE authors of a controversial Californian study that claims vitamin and mineral dietary supplements can boost children's intelligence have come under fire from British nutritional scientists, who complain that the scientific community was unable to review the findings before they were publicized on prime-time national television.

The work has also been attacked scientifically for the way its data were analysed and presented (see News and Views, page 13), but even if its conclusions turn out to be correct, the questions surrounding its handling by the authors and the media are likely to remain. In such cases, where a study's findings may affect consumer buying patterns or even government policy, critics say that the researchers should be particularly careful to submit their results to thorough peer review before public release.

The study was led by Stephen Schoenthaler, a California State University criminologist, who has been working on the links between nutrition, behaviour and IQ for a decade. He found a statistically significant increase in IQ among a group of children who were given daily supplements of vitamins and minerals. After 13 weeks, the nonverbal IQ scores of these children had improved by 3.7 points; there was, however, apparently no significant change in verbal IQ scores.

The news of these tantalizing results was out almost before they had appeared in the scientific press. The study was published in the journal Personality and Individual Differences (PID) on 26 February, as part of the proceedings of a symposium. The same night, the findings were presented on the British Broadcasting Corporation (BBC) science programme, QED.

Three years ago, QED broadcast a programme that suggested a link between nutrition and IQ, which provoked immense

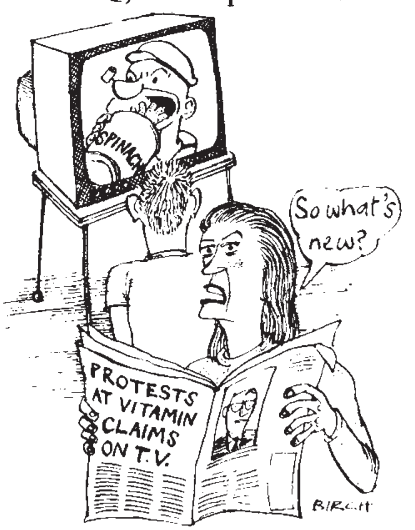

public concern and scientific controversy in the United Kingdom.

Several aspects of the study's handling are disturbing to other British scientists. Roger Whitehead, director of the Medical Research Council (MRC)'s Dunn Nutrition Unit in Cambridge and president of the

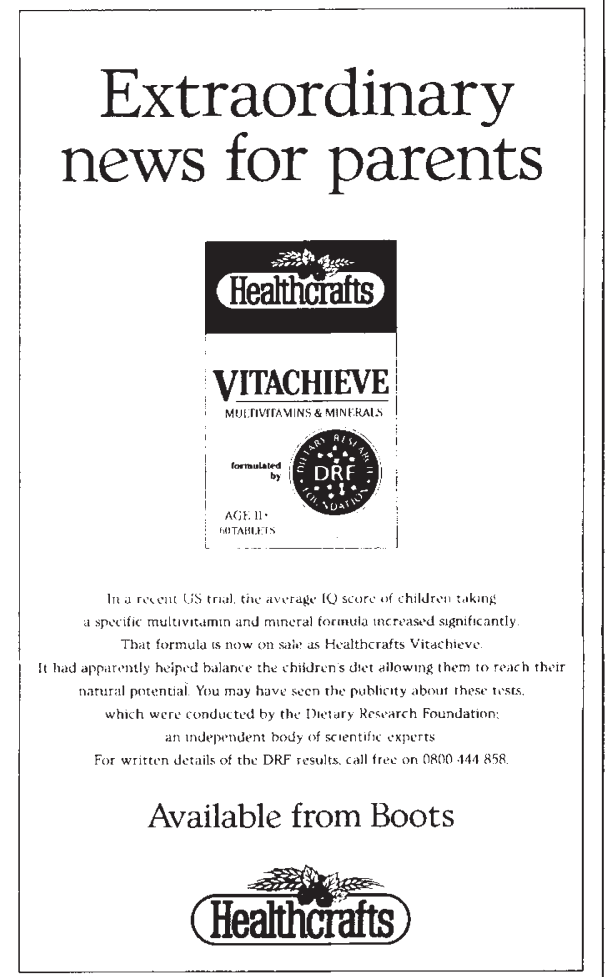

Healthcrafts' newspaper ad.

Nutrition Society, says that when research findings may have profound implications for public health, it is vital that they be properly evaluated before reaching a general audience. "There's a place for this type of television programme, but only in the light of scientific review."

And some researchers contend that the nutrition study was not given a careful enough review. For example, the meeting at which the data were discussed, which was held in San Francisco late last year, was closed to other researchers in the field.

PID, the journal in which the results were published, has a small (less than 1,000) circulation and is edited by Hans Eysenck, a co-author of the study.

Eysenck on the other hand says that the manuscript was subjected to the journal's usual process of peer review. Part of the reason for choosing PID, he says, is that publication had to be timed to precede the BBC broadcast. But Whitehead counters that other journals can publish quickly if findings are valid and important.

Some reseachers question the involvement of the BBC with the study. David Southgate, from the Agricultural and Food Research Council's Institute for Food Research in Norwich, and editor of The British Journal of Nutrition says he would have liked the manuscript to have been submitted to a peer-reviewed biomedical or nutritional journal, before the programme was made. "I don't really approve of science effectively being published on the television", he says.

The $\mathrm{BBC}$ is also marketing a book by
UNDERGRADUATE TEACHING Stanford initiative

Washington

From one of the pre-eminent research universities in the United States has come a proposal for sweeping reform of undergraduate education. Last Sunday, 3 March, Donald Kennedy, president of Stanford University, outlined a series of policy changes aimed at improving the teaching of undergraduates and lessening the tension between the research and the teaching duties of faculty members.

It is a common complaint at US universities that tenure and other personnel decisions are made mostly on the basis of a faculty member's academic research, with teaching prowess a poor second. This system excels in turning graduate students into effective research scientists, but critics say that it reduces the quality of education for undergraduates. At Stanford, at least, Kennedy hopes to improve teaching without impairing research.

Kennedy wants to switch the emphasis from quantity to quality in evaluating a scientist's research. His proposal, which must be approved by a faculty advisory board, would limit the number of publications that are taken into account when the university makes decisions on hiring, promotions, or granting tenure.

To encourage better undergraduate teaching, Kennedy both proposed changes in the way faculty members are evaluated and revealed direct financial incentives. Faculty committees should weigh not just research but also scholarly publications such as textbooks and software. And to make the rewards of better teaching palpable, Kennedy announced that $\$ 7$ million will be spent on such things as salary increases, $\$ 5,000$ awards for outstanding classroom instruction and fellowships for senior faculty members who would like to specialize in teaching.

Robert Pool

Schoenthaler, Improve your Child's IQ and Behaviour.

Whitehead is also troubled that a vitamin and mineral supplement for children, 'Vitachieve', has been launched in Britain on the basis of the results. That supplement has been endorsed by the Dietary Research Foundation (DRF), the charitable trust that funded the nutrition study. Whitehead is bothered that a supplement is being advertised in Britain on the basis of research done on Californian children. The underlying nutrition of Californian and British children is different, which may affect the results.

Eysenck responds that a study in Cumbria, northwest England, supports the Californian findings, but analysis is not yet complete. Whitehead says the British results should have been published before launching a product on the UK market. "It's absolutely essential that the data collected in Britain will be made available" for nutritionists to draw their own conclusions.

Peter Aldhous 